\title{
The impact of sustainable construction and knowledge management on sustainability goals. A review of the Venezuelan renewable energy sector
}

\author{
Licia Pietrosemoli, Carlos Rodríguez Monroy
}

\begin{abstract}
A B S T R A C T
The recognition of the relevance of energy, especially of the renewable energies generated by the sun, water, wind, tides, modern biomass or thermal is growing significantly in the global society based on the possibility it has to improve societies' quality of life, to support poverty reduction and sustainable development. Renewable energy, and mainly the energy generated by large hydropower generation projects that supply most of the renewable energy consumed by developing countries, requires many technical, legal, financial and social complex processes sustained by innovations and valuable knowledge. Besides these efforts, renewable energy requires a solid infrastructure to generate and distribute the energy resources needed to solve the basic needs of society. This demands a proper construction performance to deliver the energy projects planned according to specifications and respecting environmental and social concerns, which implies the observance of sustainable construction guidelines. But construction projects are complex and demanding and frequently face time and cost overruns that may cause negative impacts on the initial planning and thus on society. The renewable energy issue and the large renewable energy power generation and distribution projects are particularly significant for developing countries and for Latin America in particular, as this region concentrates an important hydropower potential and installed capacity. Using as references the performance of Venezuelan large hydropower generation projects and the Guri dam construction, this research evaluates the tight relationship existing between sustainable construction and knowledge management and their impact to achieve sustainability goals. The knowledge management processes are proposed as a basic strategy to allow learning from successes and failures obtained in previous projects and transform the enhancement opportunites into actions to improve the performance of the renewable energy power generation and distribution projects.
\end{abstract}

\section{Contents}

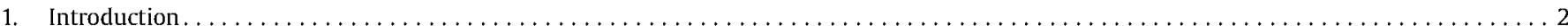

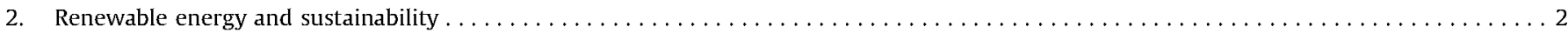

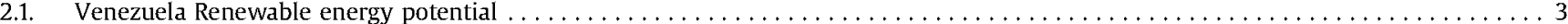

2.2. Renewable electricity infrastructure as a key issue

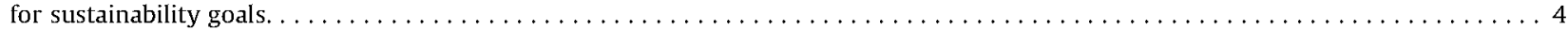

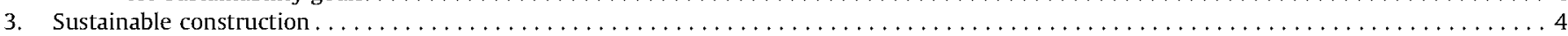

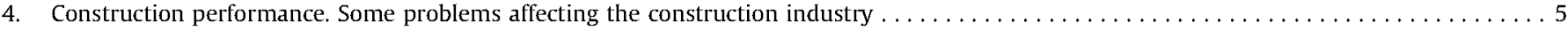

5. The renewable energy power generation projects

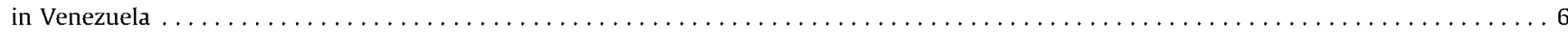

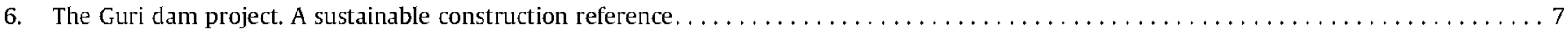

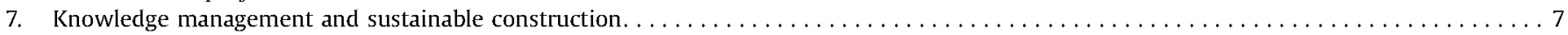

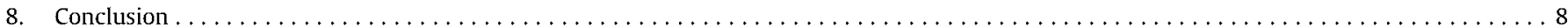

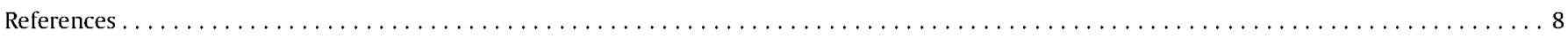




\section{Introduction}

The global society faces many issues related to poverty, political tensions, knowledge and innovation, management, ethics, economics, energy and growing environmental challenges.

The consciousness about the severe impact of fossil energies on the environment and the necessity to improve current energy patterns is rising the interest in renewable energy. Renewable energy, that comprises the use of energy free from $\mathrm{CO}_{2}$ emissions with overall unlimited potential and that can be naturally generated by the sun, water, wind, tides and modern biomass and thermal [1,2] is acknowledged as a fundamental requirement for poverty reduction and sustainable development.

From all renewable energy sources the main benefits are acknowledged to hydropower because of its abundance and availability, and also for being supported by reliable and mature technologies and infrastructures being able to supply about $19 \%$ of the planet's electricity needs [3]. Additional advantages arise from the long life cycle of infrastructures that support its generation and its relative low maintenance costs. Such advantages compensate the huge initial investments and time required for facilities construction and make hydropower to be acknowledged as essential mainly in developing countries that concentrate about two thirds of the global hydropower potential [4].

The relevance of hydropower generation is particularly sensitive for Latin American countries since they depend mostly on this energy source for about $72 \%$ of their regional needs. Brazil, Mexico, Argentina and Venezuela, among other Latin American countries depend on hydropower generation for most of their energy needs [5]. In fact, for Latin American countries hydro energy is more important than for OECD countries [6] which shows the strategic role that this type of energy has for competitiveness and regional development. This sustains the particular attention directed to ensure the improvement of this sector [7].

Additionally to the complex technical, financial and legal efforts needed, hydropower requires the support of the infrastructure necessary to generate and distribute it. Important efforts are demanded from the energy and construction sectors for this goal.

The construction and maintenance of renewable energy facilities is not easy especially for power generation units. The complex knowledge required, the unpredictable technological constraints that may arise, the huge investments needed, the conflicting economic and political interests that may appear and the social and environmental concerns show the intricate conditions that make any new project an important challenge for every country. This drives the attention to sustainable construction as a process that may integrate all such efforts to obtain long term sustainable solutions.

But attaining the goal of sustainable construction is a demanding task. Because of their complexities, the renewable energy power generation and distribution infrastructure projects are influenced by several construction problems. The main consequences of such problems are project re-programming, losses of resources and knowledge, costs overruns and delays that affect the start-up, operations and final costs of the renewable energy facilities and the services that they supply. This means that construction performance becomes another important issue to consider when planning the construction or refurbishment of large power generation facilities.

The aim of this research is to present some references about the positive relationship existing among knowledge management, sustainable construction and the global sustainability goals along with the constraints that may limit its achievement. Based on the relevance of renewable energy power generation and distribution projects for Latin America's energy supply, the Venezuelan case is presented as a reference of such connection and the possible consequences of inadequate construction performance. On the other hand, the Guri dam construction is offered as an example of sustainable construction, being considered the most emblematic large renewable energy hydropower generation project built in Venezuela. Finally, knowledge management processes are proposed as a means to take advantage from the construction lessons learned and to support the achievement of sustainability goals.

The authors of this review emphasize the importance of improving the construction performance, conscious of the global impact that it may have in areas as critical as renewable energy supply and sustainability. To be able to follow the sustainable construction path the authors propose timely knowledge management processes as the means to create and disseminate new knowledge and learn from knowledge accumulated from other projects, extracting from them the positive and negative wisdom that may support future decisions. This could make it possible to improve the renewable energy supply in order to cooperate with sustainable development. In this research authors used the wide concept of renewable energy that includes solar, wind, geothermal, biomass and hydropower sources $[1,2]$.

\section{Renewable energy and sustainability}

Sustainability has been an important issue since ancient times. Historians and philosophers in different cultures studied the consequences of soil erosion, food, water shortages or air quality and important knowledge was transmitted from their learning to current times [8]. Today sustainability concepts refer in general to the conscious production and use of the resources required for residential, industrial, transportation, commercial or recreational processes related to mankind, all supported on a long term vision and on ethical, environmental and global fundamentals which consider individuals as beneficiaries of such efforts, in order to improve their quality of life $[9,10]$.

Even though sustainability concerns are expanding with formal efforts from different countries, there are still millions of people suffering the consequences of poverty under conditions which are in total contradiction with sustainable criteria [11,12]. This constraint is particularly evident in Latin America, a region that in spite of its huge energy resources still suffers from energy supply shortages and inefficiencies [7].

Due to its capacity to offer solutions to fight poverty, the full access to energy has become an essential input for sustainable development with rising interest in the performance of this sector $[6,11,13]$ and this stresses the strong relationship between energy and sustainability.

Because of the fundamental importance of these resources the international demand for energy has been growing progressively. This demand, which is expected to increase by about 30\% for 2040 as compared to 2010 , has been driven by the demographic and economic growth, mainly related to emerging economies, especially in Asia $[2,14,15]$.

Even if experts estimate an unchanged pre-eminence of fossil energy consumption for at least until $2035[6,16]$ society in general invests important efforts to develop alternative clean energies as a fundamental element for sustainability. Besides the acknowledged traditional benefits of abundance in nature, being clean and with lower impact on global ecosystems, renewable energy today is considered also because of its potential to meet an important part of the world energy demand while offering long term sustainable solutions, since it creates wealth, employment and new business opportunities $[2,4]$.

Despite the general acknowledgement of the importance of renewable energy, experts advise that its current use is still modest since its share is around 15\% of global energy demand 
$[2,8,17]$ with only moderate expected generation increases [16] In spite of the current low share experts in general emphasize their positive growth expectations for renewable energy which are sustained by important advances of new technologies, the urgent energy needs of emerging economies and the growing environmental concerns [2].

Latin America is one of the regions where renewable energy is recognized as a critical issue since most of the countries depend heavily on hydroelectric power for their needs [18] and this supports the efforts directed to increase the availability of the large power generation infrastructure in this area. Although the energy context is very complex, important progress has been achieved on renewable and alternative energy production and use, but there is still a lot of work to do to give pre-eminence to sustainable energy.

Based on its energy potential Latin America has been a pioneer to promote important changes and reforms designed to create competitive energy markets. Initially the changes were meant to redefine the role of the states in the energy sector and so since the 1980 s this group of countries sustained different initiatives to modify their energy policies directed to liberalize and decentralize the energy markets to attract investments and to increase efficiency $[7,19]$. In some cases the reforms included the privatization of the energy generation and distribution processes among other changes. Despite the success achieved in some Latin American countries with these energy reforms, in other countries this approach created conflicts and political rejection, so initial market reforms and decentralization processes were followed by other changes directed towards returning state control of the energy system that was considered of national strategic importance [7].

Based on such different approaches the results of the Latin American reforms on energy markets vary dramatically from country to country. The different results obtained by the Latin American countries with their energy reforms have been considered as a result of their institutional framework. In some cases reforms supported positive trends in energy sector development, created a diversified energy mix with improved consumption patterns and thus reduced the social vulnerability for important portions of their societies as in the case of Brazil, Argentina, Colombia and Chile [6]. This group of countries presents better results than other neighboring countries which still face important shortages and inefficiencies. In fact, the region is still not able to fully satisfy the energy needs of important sectors of its society which suffer the low levels of electrification, low infrastructure investment with inefficient and insufficient renewable energy sources. One such case is Venezuela that in spite of huge hydropower and fossil fuel resources still presents important improvement opportunities for the efficiency and reliability of its energy sector $[16,19,20]$.

Based on such differences and on the regional energy potential, experts realize the need to improve such core activities to be able to assure energy supply, foster regional development and the fight against poverty, thus supporting sustainable social development [7] which means opportunities to improve energy markets with increased participation of renewable energy in order to be more efficient and less dependent on fossil energy [4].

Since the main expected increases in renewable energy supply in Latin America are related to hydroelectric power [16] and Venezuela is one of the largest hydropower producers in the world $[4,16,21]$ this makes this country an interesting reference to evaluate its potential to improve renewable energy power generation and distribution in combination with its sustainable construction efforts.

\subsection{Venezuela Renewable energy potential}

Venezuela has an energy tradition which started at the end of nineteenth century with the use of oil from a commercial perspective. In 2011 the country occupied the eighth position as world producer of crude oil. Current oil and gas reserves make it one of the countries with the greatest hydrocarbon potential in the world. Additionally to the fossil energy resources, Venezuela is also known for being the ninth world producer of hydroelectric power [14] with exceptional geographical and hydrological conditions for the development of hydropower projects [22].

With this endowment the Venezuelan renewable energy sector is able to supply most of the country's energy needs and has an important potential to grow. In 2009 about $70 \%$ of the Venezuelan electricity demand was met by the large hydropower generation facilities built to use the water resources of the Caroni River [20].

Table 1 presents some data on the evolution of renewable energy supply in Venezuela and other Latin American countries compared with their own total energy production.

According to such data, from 2000 to 2009, Venezuela increased the renewable energy supply by $2.15 \%$ while Brazil increased it by $8.35 \%$, Uruguay by $3.04 \%$ and Chile by $1.93 \%$. The rest of these countries evidenced lower positive variations or even decreased their renewable energy supply. In the aggregate the Latin American and Caribbean countries included in such study increased their supply of renewable energy by $1.69 \%$ when comparing 2009 with 2000. From all its energy supply in 2009 Venezuela had a renewable energy share of $11.5 \%$ [23], but

Table 1

Evolution of renewable energy supply for some Latin American countries (Percentages). Source: Authors'adaptation based on [23].

\begin{tabular}{|c|c|c|c|c|c|c|c|c|c|c|c|}
\hline$-a^{a}$ & 2000 & 2001 & 2002 & 2003 & 2004 & 2005 & 2006 & 2007 & 2008 & 2009 & Variation (\%) 2009-2000 \\
\hline Argentina & 9.0 & 10.9 & 10.8 & 9.9 & 8.6 & 9.3 & 10.0 & 7.8 & 8.7 & 9.4 & 0.37 \\
\hline Bolivia & 23.0 & 26.3 & 20.6 & 20.8 & 18.1 & 15.6 & 15.5 & 17.2 & 16.0 & 17.7 & -5.31 \\
\hline Brasil & 35.3 & 34.8 & 36.7 & 39.7 & 38.7 & 40.0 & 41.0 & 42.5 & 42.4 & 43.6 & 8.35 \\
\hline Chile & 21.1 & 22.7 & 22.3 & 21.2 & 21.1 & 21.6 & 21.1 & 19.4 & 21.1 & 23.0 & 1.93 \\
\hline Colombia & 27.8 & 27.5 & 28.6 & 27.8 & 24.8 & 24.5 & 25.5 & 25.3 & 24.9 & 23.5 & -4.31 \\
\hline Ecuador & 17.7 & 16.7 & 18.1 & 15.7 & 12.9 & 11.7 & 14.8 & 13.5 & 14.1 & 11.0 & -6.62 \\
\hline Guyana & 41.5 & 41.7 & 41.8 & 41.9 & 41.6 & 45.1 & 48.0 & 43.8 & 43.1 & 42.7 & 1.16 \\
\hline Paraguay & 66.4 & 67.7 & 64.3 & 64.1 & 66.4 & 68.9 & 67.7 & 67.5 & 65.8 & 67.5 & 1.06 \\
\hline Perú & 28.8 & 31.2 & 31.4 & 33.2 & 30.5 & 28.2 & 31.2 & 30.5 & 25.3 & 22.5 & -6.27 \\
\hline Suriname & 20.9 & 19.9 & 20.4 & 20.6 & 20.3 & 20.1 & 20.2 & 20.2 & 20.2 & 20.2 & -0.73 \\
\hline Uruguay & 30.5 & 40.2 & 43.0 & 42.0 & 34.3 & 35.4 & 30.1 & 36.7 & 33.8 & 33.6 & 3.04 \\
\hline Venezuela & 9.4 & 9.3 & 9.7 & 8.9 & 10.5 & 10.6 & 9.4 & 11.9 & 12.0 & 11.5 & 2.15 \\
\hline Latin-American \& Caribbean ${ }^{\mathrm{b}}$ & 21.5 & 21.6 & 22.4 & 22.8 & 22.5 & 22.2 & 22.3 & 23.2 & 23.0 & 23.2 & 1.69 \\
\hline
\end{tabular}

\footnotetext{
${ }^{a}$ Corresponds to the offer of following energetic sources: geothermal, hydroelectricity, wood (portion considered sustainable), cane products and other renewable sources (as solar and wind) (\%).

${ }^{b}$ Includes the countries for which there is information available (\%).
} 
considering the country's energy hydropower potential and existing infrastructure a better achievement could be expected especially to reduce the dependence on fossil fuels.

Venezuelan energy generation mix is also characterized by the expensive energy consumption patterns. In fact, Venezuela shows historical primary energy consumption per capita that exceeds the worlds' and Latin American and Caribbean trends [24]. The same behaviour with energy use in Venezuela is shown with electric power utilization as the country shows higher per capita electricity consumption than the world and Latin American averages. Those negative trends are additionally worsened as the country presents a low efficient use of energy [20,24].

Understanding the complexities of a problem that cannot be simplified (i.e. in Venezuela the scarcity of railroads creates a dependence on road transportation and thus on fossil fuel) the authors of this research intend to point out a behavior that from a global perspective seems contrary to long term sustainable goals. In fact, Venezuelan hydropower is decreasing with respect to fossil energy sources. In the period 2006-2009 the share of thermal energy supply increased from $27 \%$ to $36 \%$ [20]. The Venezuelan energy patterns present opportunities to develop the country's renewable energy potential that is highly dependent on the existing energy infrastructure as will be described below.

\subsection{Renewable electricity infrastructure as a key issue for sustainability goals}

Nations have faced the challenge to build important infrastructures since ancient times. Currently the growing recognition of energy as part of the solutions for society needs to draw attention to the evolution of the infrastructure projects related to energy production, distribution and use as a way to improve quality of life and to support sustainable development. In fact, none of the Millennium Development Goals would be possible without the investments required to provide the modern and clean energy supplies needed for billions of people. This is why among other key factors required to expand renewable energy sources we find the construction of large power generation infrastructure needed to generate and distribute it. The development of such infrastructure - for the improvement of existing facilities or the construction of new ones - demand many construction efforts from researchers, designers, financiers, owners, clients and constructors.

The availability of an adequate infrastructure for water, energy, roads, industry or communications has been identified as a fundamental element for the productivity and competitiveness of nations. In fact, the conditions of such infrastructure have an important effect over national costs, logistics and processes in general. They also have influence on population health and educational levels and may reduce income inequalities $[9,25]$.

To meet the increasing energy demand multidisciplinary complex efforts, years of work and huge investments are required because of all the technical, financial, geopolitical and environmental challenges and risks related to any project to be implemented [15]. Depending on the nature of the project and the building performance it can take around 2 years to build a natural gas or renewable energy plant [15], around 3 years to build a combined cycle generation plant [26], more than 5 years to build a nuclear power plant [15] and around 10 years to build a large hydropower generation facility [26].

Table 2 shows the evolution of some of the world's infrastructure stocks in the last 50 years and highlights the prominence of the energy infrastructure.

Fay and Yepes [25] calculated how the electricity generating capacity should increase in the period 2000-2010, being ranked as the second infrastructure investments needed. Sustaining such priority, the IEA [16] estimates the need to invest in energy
Table 2

How the relative composition of infrastructure stocks has changed in 50 years, all countries.

Source: Authors' adaptation from [25].

\begin{tabular}{|c|c|c|c|c|c|c|}
\hline & $\begin{array}{l}1960 \\
(\%)\end{array}$ & $\begin{array}{l}1970 \\
(\%)\end{array}$ & $\begin{array}{l}1980 \\
(\%)\end{array}$ & $\begin{array}{l}1990 \\
(\%)\end{array}$ & $\begin{array}{l}2000 \\
(\%)\end{array}$ & $\begin{array}{l}2010 \\
(\%)\end{array}$ \\
\hline Electric generation & 22 & 32 & 40 & 43 & 44 & 42 \\
\hline Roads & 47 & 46 & 45 & 44 & 44 & 43 \\
\hline Railways & 29 & 19 & 13 & 9 & 6 & 5 \\
\hline Telecommunications & 2 & 3 & 3 & 4 & 6 & 10 \\
\hline Total & 100 & 100 & 100 & 100 & 100 & 100 \\
\hline
\end{tabular}

Excludes: Oil, gas, ports, airports, water and sanitation.

infrastructure to be able to meet global energy demand, so the building of new renewable plants and the refurbishment and maintenance of existing ones become one of the main goals to sustain socio-economic growth and competitiveness in developing countries.

The need to make important investments to develop energy infrastructure is a priority for Latin American countries in order to make it possible for them to achieve their regional energy goals [7] and this makes evident the importance to obtain the best construction performance possible and drives the attention to sustainable construction as a means to reach sustainable development goals.

\section{Sustainable construction}

The possibility to supply shelter, schools, water and energy systems, industry, communications, commercial or leisure facilities, alongside jobs and revenue generated make construction one of the main activities worldwide. The positive impact of construction for mankind's evolution has led to the consideration of this industry as one of the main drivers of social and economic change because it allows the creation of new wealth for society $[9,27,28]$.

Construction has evolved with the use of new sustainable materials and equipments, the modularization of buildings and structures, the prefabrication of elements, the development of construction supply chain initiatives, the improvement of quality and productivity, as well as with the use of innovation and hightech solutions required today in many new construction projects [9,29-31]. By this means construction today can be considered a high-tech and knowledge-driven industry.

With its progress construction has become more complex and challenging. To be feasible any construction must take into consideration multiple issues related to technical constraints, resources such as energy and water, environmental, social, cultural and economic issues. All these challenges frequently become more intricate while the projects get larger, more complex and are developed in remote locations [31,32]. This has led to the understanding of the importance of sustainable construction.

Sustainable construction has been described as the result of the common efforts of investors, construction leaders, service representatives, industry suppliers, communities and other stakeholders directed to develop new building considering the environmental, energy, socio-economic and cultural conditions needed to bring integral solutions to society. In practice, it is based on the application of sustainable guidelines for construction processes, with the final goal of improving quality of life and developing the potential of mankind [9,27,28,32-35].

Developing projects under the guidelines of sustainable construction is not easy because projects are frequently subject to problems that constrain their execution. So the timely understanding of limitations and the establishment of the strategies needed to improve construction may become a key issue to 
address projects into the path of sustainable construction and sustainable development [33] and this demand from construction implies additional efforts to include sustainable processes in the different activities involved in any project [33].

\section{Construction performance. Some problems affecting the construction industry}

The multiple variables involved in construction projects force developers and constructors to face numerous challenges that sometimes become very problematic. Those variables are related to aspects that may include technical specifications, design, re-engineering, construction techniques, as well as environmental, economic, safety, cultural, social, quality control, human resource, financial and management issues.

In addition, constructors have to answer the demands of the project owners, customers and communities while complying with the strict quality standards and regulations needed for each project. All those challenges are currently more difficult because of the global crisis, political stress or even the occurrence of natural disasters. In general, infrastructure projects are subject to many risks and construction problems [36] that may influence contracts as diverse as the building of off-shore oil facilities in the North Sea or the refurbishment of hydropower facilities in the Caroni River in Venezuela. In fact, the construction projects frequently present delays and other deviations from conditions agreed between the parts $[9,37-40]$.

Time and costs overruns are very common problems affecting projects in different countries all over the world and often the construction projects are not completed according to the original schedule. In a study developed in Saudi Arabia, Assaf [38] described that $70 \%$ of the construction projects that participated on the survey suffered delays from $10 \%$ to $30 \%$ of the original execution time planned.

Sambasivan [39] found that the main causes affecting the projects' performance were related to financing and payment delays, insufficient contractor experience, owner interference, problems with productivity and slow decision making, among other.

Delays also depend on changes in the design and scope of tasks during the construction phase, contractor's performance, quality deviations between performance and plans, delays in making decisions and approvals by owners, financial problems, difficulties in obtaining work permits and coordination and communication problems [41].

The origin of all such problems may go from underestimating project scope, project uncertainties and non-realistic forecasts about job complexity, costs or revenues [35]. Some other constraints may depend on specific policies and conditions present in a given country $[9,10,39]$. Table 3 , presents a summary of the main problems identified by several authors which affect construction performance of projects executed in different countries.

Besides these problems, construction projects are frequently constrained by some other intangible concerns related to the difficulty to determine the true origin of project deviations, the shortage of structures, systems and processes designed to preserve, share and create new knowledge, or the lack of knowledge and reliable data. Additional problems depend on the lack of understanding or interest in issues related to sustainability or knowledge management that are frequent in public or private construction [42-45]. Other knowledge management problems for construction derive from the fragmented and temporary nature of the construction industry that makes the loss of knowledge frequent because of personnel transfer to other projects, difficulties in capturing, organizing and retrieving acquired knowledge,
Table 3

Main problems affecting construction performance.

Source: Authors' summary from $[27,29,30,35,36,38-42,47]$.

Financial
Client not paying on time+high costs, inflation
Lack of capital/credit facilities - dificulties to arrange guarantees
Excess of costs over budget-dificulties to recover over-costs with clients
Technical conditions
Technical/specification/contractual shortages+change orders
Jobsite conditions/interferences
Project extention of time
Quality deviations/quality control problems
Physical resources
Material and equipment availability and costs
Material and equipment looses-general resources wastes
Reduced productivity levels-time lost
General conditions
Poor quality of general performance
Change in government regulations/economic-political instability/adverse
weather
Low investment on urban and or construction sustainability

Table 4

Main knowledge problems affecting construction performance. Source: Authors' summary from $[42-45,59,60]$
Intangible resources/knowledge

Unforeseen circumstances

Limited construction problems understanding or interest+data shortages

Planning and design problems

Lack of leadership and responsibility/deficient management/informal systems

Lack of workmanship/technical/business management skills

Knowledge, knowledge management and communication shortages

Limited understanding and interest about sustainable construction

deficient effectiveness of lessons learned or shortage of skilled workers $[42,44]$.

In a study developed in Malaysia in an electrical substation, Lim and Zain Mohamed [37] found that the most recurring problems were related to human performance and were manifested as lack of experience and knowledge, different opinions of team members, inherited problems from earlier phases or deficient overall view of the project. Table 4 summarizes some of the main knowledge and intangible problems identified as causes of construction problems in different projects.

In general, all these problems frequently generate project delays, loss of knowledge [44], the disruption of tasks, loss of productivity and revenue because of reduced or no production due to facilities' delays, the dependence on present facilities that may be insufficient or inadequate, higher overhead costs through inflation, labor, materials and other direct cost increases [41] thus producing a negative impact for project beneficiaries, through augmented legal and financial risks and reduced benefits for owners and society.

Additional consequences of construction problems and the limitations that they bring for infrastructure development are related to the constraints imposed on the capacity of the countries to be competitive and grow, to reduce poverty and improve the quality of life. In fact, Holm [4] and Fay and Morrison [46] describe the poor quality and scarce infrastructure available in Latin America as a severe limitation for regional competitiveness and emphasize that the region has lost part of its competitive position in relation to other regions, i.e. the East Asian countries or China, that have improved their infrastructure. These authors also underline that the infrastructure problems establish limitations to improve income distribution and to reduce poverty.

At the end, all these project delays and cost overruns create a very harmful situation of claims, delays on plant start-ups, production delays, lost competitiveness, scarcity of goods, distressed clients, consumers and society and a severe weight on public and private 
budgets because final projects cost much more than originally planned and are finalized several months or years later.

Some of the problems described above are present in Venezuela because of limited allocation of resources or non-competitive orientation of the investments made. Similarly, as with other infrastructure sectors, this constrains the construction of new renewable energy plants or the maintenance of existing ones with negative consequences for the services that they must deliver to society $[20,47,48]$.

Because of the risk and consequences mentioned it is essential for energy, construction and industrial stakeholders to understand the impact of construction problems. Some facts regarding the development of renewable energy power generation and distribution projects in Venezuela are presented as a reference of the direct impacts and lessons learned that may be extracted from these construction problems.

\section{The renewable energy power generation projects in Venezuela}

Describing renewable energy power generation and distribution projects in Venezuela must be done considering the limited availability and accuracy of solid data and official statistics. In fact, Holm [4] points out that in general developing countries suffer the consequences of non-reliable data while Fay and Morrison [46] state than in particular Latin America faces problems of insufficient data about infrastructure among other. Sequera [49] and de la Vega [50] sustain that mainly due to cultural reasons Venezuela is characterized by structural gaps and limitations in statistics and indicators.

In recent years Venezuela has been investing abundant resources in the power sector infrastructure in order to increase the generation and transmission capacity to supply the power needed to meet demand. In fact, for the period 2008-2014 the Venezuelan government planned to increase the electricity supply with $10,420 \mathrm{MW}$ of additional generation capacity coming from the construction of new plants or the refurbishment of existing facilities located around the country, i.e. the hydroelectric plants Simón Bolívar (Guri), Antonio
José de Sucre (Macagua I), Manuel Piar (Tocoma), Fabricio Ojeda (La Vueltosa) or thermoelectric plant such as Ezequiel Zamora, Alberto Lovera, Juan Manuel Valdez (CIGMA), Termozulia or Josefa Camejo, among others.

Table 5 shows the current progress for some of the infrastructure projects for hydropower generation under development in Venezuela for the period 2008-2014.

Table 6 presents the progress of some of the energy infrastructure projects for thermoelectricity generation under development in Venezuela for the same period.

Regarding wind generation the Venezuelan government has initiated the construction of the Paraguaná wind-farm project located in the Falcón state to install 76 wind turbines with a total installed capacity of $100 \mathrm{MW}$ and La Guajira wind-farm project located in the Zulia state to install 12 turbines for a total installed capacity of $24 \mathrm{MW}$. Other wind-farms are planned to be built in other states. Currently there is only limited official information available related to the status of such projects as well as for solar photovoltaic ones. Although available data is not enough to conclude what really happens with the development of renewable energy projects in Venezuela the current set of completion and the non-compliance with the scheduled start-up show that there are important problems affecting this sector.

Acknowledging the existence of problems for this sector, the Venezuelan energy organization Corpoelec [51] refers that some time overruns affecting the projects in progress are caused by low labor productivity, conflicts created by local communities, difficulties in purchasing and importing machinery, materials and equipments, as well as legal, contractual, financial and construction delays.

Confirming such appreciations Portillo [52] states that the important efforts oriented to improve the Venezuelan energy infrastructure have been limited because the construction sector in Venezuela suffers from the effect of legal and financial constraints that generate conditions marked by the preeminence of political over technical decisions, frequent strikes and conflicts at worksites, foreign currency restrictions, restrictive labour regulations, technical, labour, knowledge or material constraints,

Table 5

Venezuelan main generation projects-hydroelectricity.

Source: Authors' elaboration from [51].

\begin{tabular}{|c|c|c|c|c|c|c|}
\hline Plant & Project & State & Capacity MW & Project beginning & Scheduled start-up & Of completion in Nov $2012(\%)$ \\
\hline Simón Bolívar (GURI) & Refurbishment & Bolívar & 700 & 2001 & 2014 & 35.00 \\
\hline Manuel Piar (TOCOMA) & New plant construction & Bolivar & 2160 & 2002 & $2012 G-12014 G-10$ & 66.26 \\
\hline Fabriio Ojeda (La Vueltosa) & New plant construction & Mérida & 514 & 2004 & 2010 & 71.80 \\
\hline Antonio J. de Sucre (Macagua I) & Refurbishment & Bolívar & 120 & 2006 & 2014 & 43.60 \\
\hline
\end{tabular}

Table 6

Venezuelan main electric generation projects 2008-2014-Thermoelectricity. Source: Authors' elaboration from [51].

\begin{tabular}{|c|c|c|c|c|c|c|}
\hline Plant & Project & State & Capacity MW & Project beginning & Scheduled start-up & Of completion in Nov $2012(\%)$ \\
\hline Planta Centro & Refurbishment & Carabobo & 400 & 2002 & 2009 & 62.00 \\
\hline Antonio José de Sucre & New plant construction & Sucre & 1000 & 2004 & 2012 & 15.30 \\
\hline Alberto Lovera & New plant construction & Anzoátegui & 300 & 2005 & 2010 & 48.30 \\
\hline Ezequiel Zamora & New plant construction & Guárico & 150 & 2005 & 2009 & 43.60 \\
\hline Bachaquero & New plant construction & Zulia & 470 & 2007 & 2011 & 20.40 \\
\hline Tamare & New plant construction & Zulia & 470 & 2007 & 2012 & 18.73 \\
\hline Termozulia II & Expansion to combined Cycle & Zulia & 470 & 2007 & 2010 & 70.23 \\
\hline Termocentro & New plant construction & Miranda & 1610 & 2007 & 2011 & 7.60 \\
\hline Juan Manuel Valdez (Cigma) & New plant construction & Sucre & 900 & 2007 & 2014 & 8.00 \\
\hline San Diego de Cabrutica & New plant construction & Anzoátegui & 300 & 2008 & 2009 & 17.57 \\
\hline Josefa Camejo & New plant construction & Falcón & 450 & 2009 & 2009 & 91.70 \\
\hline Termoisla & Repowering & Nueva Esparta & 316 & 2009 & 2010 & N/A \\
\hline
\end{tabular}


inflation and inefficient bureaucracy that make it harder to complete the projects [47]. The combination of all such problems causes important time and cost overruns and in general results in poor project overall performance, clients' disappointment, claims and additional distress for the Venezuelan society.

Additionally to the other problems affecting this industry, Venezuela is among the countries with highest power transmission and distribution losses in the world [46]. This problem, along with time overruns shown in previous tables, makes it harder for Venezuela to be able to meet its energy demand. In fact, in part because of the time overruns of some of the projects described above and in part because of delays in the arrival of the rainy season that caused water shortages in the Caroní river basin, the electricity authorities were forced in 2010 to start with an electricity rationing program in an attempt to reduce electricity demand while the country's generating capacity was increased [16,53].

This means that together with the direct consequences of time and cost overruns that Venezuela faces because of such problems, additional consequences are suffered by large segments of society due to energy scarcity and power outages that hurt citizens' quality of life and Venezuelan production performance because of alterations in industry and trade [52]. This severely limits the possibility to improve the country and regional competitiveness and its fight against poverty.

The revision of the Venezuelan energy endowment and learning from the energy projects in progress and the constraints that affect the performance of construction in general show the opportunities that the country presents to make better use of its potential. Moreover, the Venezuelan energy infrastructure case that requires further research - is not a problem confined only to the country's borders. In fact, literature and empirical evidence demonstrate that construction constraints are present in several developed and developing countries and have a great impact on energy and industrial projects.

From a complementary perspective Venezuela also has renewable energy power generation infrastructures to be considered as positive references. In fact, the Guri dam building is described as a sustainable construction reference from which it is possible to learn how to improve current projects' performance as described below.

\section{The Guri dam project. A sustainable construction reference}

The main efforts for the electrification of Venezuela started in the decade of 1940 . The goal was to create a water reservoir to provide hydropower to guarantee the country's needs, partially replacing the fossil fuels and promoting the industrial development of the region based on the hydraulic potential of the lower Caroni River Basin [54]. The process started with the construction of the Raul Leoni hydroelectric plant, also known as the Guri dam, located in the southern region of Venezuela and was followed by other dams such as Caruachi and Macagua I. The engineering studies for the Guri dam started in 1953. From the beginning particular attention was placed on issues related to the quality, technical specifications, bidding, sustainable development, legal, financial, safety, environmental, risk management, communication, training and knowledge variables of the project.

This included formal processes to evaluate and understand the lessons learned during the different stages of the project to guarantee its success. Specific awareness was put in the project planning and creation of controls and supervision modes to prevent and reduce technical, environmental or financial risks and sustain the adequate management of all the resources involved [54].

Given the limitations existing in Venezuela on the availability of engineering and contractors' capacity, the early stages of the project were managed by international companies. Gradually, the transfer of knowledge enabled the final construction stage to be performed by Venezuelan contractors who achieved up to $60 \%$ of the construction effort.

The project was developed with the financial support of the World Bank together with the Venezuelan government. Initially the Guri dam was planned to have a generation capacity of $2865 \mathrm{MW}$, but due to the success of the first stage and the increased energy demand the project was completed with a second stage with an added generation capacity of $7300 \mathrm{MW}$. The whole process took 23 years to be completed, from 1963 to 1986 , and placed Guri as the second largest hydropower plant in the world [54-56].

Important changes took place during the Guri dam construction. Among other, Venezuela suffered a devaluation that created significant cost overruns. The financial controls made it possible to correct the deviations still on time, and finally the project was executed within the planned budget. Some other technical, financial or labor problems were revised continuously and timely strategies were implemented to correct deviations and thus reduce construction delays [54,57].

The attention to quality, the good teamwork created by the international and national companies and the workers, the timely evaluation of the project deviations, the use of innovations and the implementation of the corrective measures together with the financial controls were considered success factors for the Guri project. All these strategies permitted a successful budget management and the whole project was completed 15 days ahead of schedule. Additionally, the Guri dam achieved several technical records that are a reference for hydroelectric projects [54,57]. Other important hydropower projects developed in Venezuela, such as Caruachi and Macagua confirm this positive performance [56].

Along with the valuable use of the renewable energy resources of the Caroni River, the Guri project also enabled the development of the basic industries of iron, steel and aluminum and created important knowledge references about the construction of renewable energy power generation and distribution projects.

\section{Knowledge management and sustainable construction}

Knowledge is the result of a combination of expertise, values, personal approach, know-how, technical abilities, skills, successes and failures that individuals and organizations acquire from personal, social and organizational interaction. Since construction has become a knowledge-driven industry, the proper management of all the knowledge involved has become a fundamental element to address activities under the sustainable construction path.

To achieve this goal construction counts on the support of knowledge management as a key process that enables capability and innovation development, cultural changes, the transfer of knowledge and lessons learned from the various stages of each project and from one project to others. This allows better decision making, performance and competitiveness improvements and customer satisfaction thanks to the reduction of mistakes and of work repetition and allows an easy adaptation to changing conditions while promoting construction sustainability and sustainable development $[44,45,58,59]$.

Knowledge management processes may be completed thanks to the support of systems, procedures and models available. In fact, during the last decades different models of knowledge management have been proposed by experts as, for example, the SECI Model (Socialization, Externalization, Combination and Internalization) proposed by Nonaka and Takeuchi [60], the Intelligent Knowledge Management Methodology (MEGICO) proposed by del Moral et al. [61], the BIM (Building Information Models) [62] or the 
specialized construction oriented model CLEVER (Cross-sectoral Learning in Virtual Enterprise) proposed by Kamara et al. [45].

Beyond the knowledge management models there is a vast range of resources that offer valuable support to construction performance $[63,64]$. Among them we find the supply chain collaborative practices. Even if traditionally oriented to manufacturing industries, those practices are valued in construction because they effectively support knowledge management processes. This brings valuable benefits to all construction phases from design and planning to management of built facilities since they allow the coordination of the different processes and enhance the flow of knowledge involving all stakeholders in the construction project [64].

Research demonstrates that in spite of the growing recognition of the importance of knowledge management for construction performance, in reality there are still limitations in the mechanisms and organizational practices available to promote knowledge creation, sharing and reuse which imply lost opportunities to profit more from such valuable resources to solve some of the construction problems described in this research. In order to be able to reach the sustainable construction goal the construction industry must intensify the efforts oriented to improve the use of such intangible resources [33,42-45,59]. In fact, one of the main issues for construction is finding the way to give the existing knowledge the practical use for the solution of the construction problems described above.

\section{Conclusion}

The paths to reach sustainable development goals are diverse and complementary. In this research authors underline the important nexus existing among sustainable construction, knowledge management, renewable energy and sustainability and identify the energy infrastructure as a fundamental issue to facilitate the increase in the supply of renewable energy in the global markets. This is particularly relevant for developing countries, having Latin America and in particular Venezuela as important references for such learning.

To be capable of meeting the growing energy demand the energy infrastructure must be delivered according to specifications following sustainable construction guidelines. But this is frequently limited because of the construction problems that arise in any kind of construction projects. The timely identification of such problems and the lessons learnt from the positive and negative experiences accumulated are essential in order to improve construction performance. The Venezuelan case presented in this article provides important conclusions for energy stakeholders, including constructors.

The country's energy potential, the delays with some current energy projects and the lessons learned from the construction of the Guri dam show the improvement opportunities which exist for this sector in order to be able to complete the infrastructure projects needed to meet the growing energy demand. The experience obtained from the Venezuelan case is applicable to other scenarios, particularly in Latin America, and the knowledge generated should enrich future projects to avoid the repetition of problems.

This requires that stakeholders be aware of common duties and, with the support of knowledge management processes, be able to make better decisions for the future, improving therefore the sustainability goals.

This research article has introduced a first approach for the general understanding of a complex problem that affects the energy and construction industries. Subsequent and formal studies are needed to provide further conclusions, especially to supply accurate data about problems that have not been fully studied, particularly in Venezuela. Future research will continue along this path.

\section{References}

[1] Graßl H, Kokott J, Kulessa M, Luther J, Nuscheler F, Sauerborn R, et al. Towards sustainable energy systems. WBGU. German Advisory Council on global change 2003.

[2] Muneer T, Asif M. Energy supply, its demand and security issues for developed and emerging economies. Renewable and Sustainable Energy Reviews 2007; $11: 1388-413$

[3] Oliver Paish. Small hydropower: technology and current status. Renewable and Sustainable Energy Review 2002;6:537-56.

[4] Holm D. Renewable energy future for the developing world. ISES International Solar Energy Society 2010. 〈http://whitepaper.ises.org 〉.

[5] Hugh Rudnick, Juan Pablo Montero. Second generation electricity reforms in Latin America and the California paradigm. Journal of Industry, Competition and Trade 2002;2(1/2):159-72.

[6] Zilio M, Recalde M. GDP and environment pressure: the role of energy in Latin America and the Caribbean. Energy Policy 2011;39(12):7941-9.

[7] Mocarquer S, Barroso L, Rudnick H, Bezerra B, Pereira M. Balance of power IEEE Power and Energy Magazine 2009 (Sept/Oct).

[8] Jefferson M. Sustainable energy development: performance and prospects. Renewable Energy 2006;31:571-82.

[9] CIB \& UNEP-IETC. Agenda 21 for sustainable construction in developing countries. Boutek Report Bou/ E0204. 2002.

[10] Oltre la crisi. Beyond the crisis. Techne: Journal of Technology for Architecture and Environment. Firenze University press. 01/2011.

[11] Bhide A, Rodríguez. Monroy C. Energy poverty: a special focus on energy poverty in India and renewable energy technologies. Renewable and Sustainable Energy Reviews 2011;15:1057-66.

[12] Chen S, Ravallion, $M$. The developing world is poorer than we thought but not less successful in the fight against poverty. The World Bank Development Research Group; 2009. Policy Research Working Paper 4703.

[13] Kothari R, Tyagi V, Pathak A. Waste-to-energy: a way from renewable energy sources to sustainable development. Renewable and Sustainable Energy Reviews 2010;14:3164-70.

[14] BP. BP Statistical review of world energy. bp.com/statisticalreview. Revised; September 2012

[15] Exxon Mobil; 2012 The outlook for energy: a view to 2040. exxonmobil.com energyoutlook.

[16] US Energy Information Administration EIA. International Energy Outlook 2011 DOE/EIA-0484; 2011

[17] Taibi E, Gielen D, Bazilian M. The potential for renewable energy in industrial applications. Renewable and Sustainable Energy Review 2012;16:735-44.

[18] Ronald Fisher, Pablo Serra. Regulating the electricity sector in Latin America. Economía 2000;1(1):155-98 (Fall).

[19] Paul Suding. Opening up a transition, success and problems. Energy Policy 1996;24(5):437-45.

[20] Bautista S. A sustainable scenario for Venezuelan power generation sector in 2050 and its costs. Energy Policy 2012;44:331-40.

[21] reFocus. RE in Latin America; January/February 2005. 1471 0846/05.

[22] Revista de obras públicas. Presa y central de Caruachi. Un emblemático proyecto hidroeléctrico en Venezuela; December 2001. N. 3416. p. 39-56.

[23] Cepalstat 2012. 〈http://websie.eclac.cl/sisgen/Consultalntegrada.asp >. Revised September 2012

[24] World Bank. 〈http://data.worldbank.org〉. Revised; September 2012.

[25] Fay M, Yepes T. Investing in infrastructure: what is needed from 2000 to 2010 ? World Bank Policy Research Working Paper 3102; July 2003.

[26] Arango S, Larsen E. The environmental paradox in generation: how South America is gradually becoming more dependent on thermal generation. Renewable and Sustainable Energy Reviews 2010;14:2956-65.

[27] Winch G. Managing construction projects.USA: Wiley-Blackwell; 2010.

[28] Consiglio Nazionale del economia e del lavoro. Una politica industriale sostenibile nel setttore delle costruzioni; 2001. VI Comissione in sede deliberante.

[29] Anumba C, Egbu C, Carrillo P. Knowledge management in construction. Blackwell Publishing; 2005.

[30] Koskela L. An exploration toward a production theory application to construction. Technical Research Center of Finland. VTT Publications 2000:408

[31] European Commission. Accelerating the development of the sustainable construction market in Europe. Com; 2007860 final.

[32] Comission of the European Communities. Midterm progress report of sustainable construction. Commission staff working document. Sec; 20091198 final.

[33] Shelbourne M, Bouchlaghem D, Anumba C, Carrillo P, Khalfan M, Glass J. Managing knowledge in the context of sustainable construction. Itcon: Journal of Information Technology in Construction 2006;11.

[34] Ortiz O, Castells F, Sonnemann G. Sustainability in the construction industry: a review of recent developments based on LCA. Construction and Building Materials 2009;23:28-39.

[35] Gomes V, Gomes M. Exploring sustainable construction: implications from Latin America. Building Research and Information 2005;33(5):428-40.

[36] Doh J, Ramamurti R. Reassessing risk in developing country infrastructure. Long Range Planning 2003;36:337-53. 
[37] Lim C, Zain Mohamed M. An exploratory study into recurring construction problems. International Journal of Project Management 2000;18:267-73.

[38] Assaf S, Al-Hejji S. Causes of delay in large construction projects. International Journal of Project Management 2006;24(4):349-57.

[39] Sambasivan M, Soon Y. Causes and effect of delays in Malaysian construction industry. International Journal of Project Management 2007;25:517-26.

[40] Flyvbjerg B, Garbuio M, Lovallo D. Delusion and deception in large infrastructure Projects. Two models for explaining and preventing executive disasters. Californian Management Review 2009;51(2):170-94.

[41] Abdul-Rahman H, Berawi M, Berawi A, Mohamed O, Othman M, Yahya I. Delay mitigation in the Malaysian construction industry. Journal of Construction Engineering and Management 2006 (ASCE. February).

[42] Kazi A. Knowledge management in the construction industry: a socio technical perspective. Idea Group Publishing; 2005.

[43] Love P, Fong P, Irani Z. Management of knowledge in project environments Elsevier; 2005.

[44] Tan H, Anumba C, Carrillo P, Bouchlaghem D, Kamara J, Udeaja C. Capture and reuse of project knowledge in construction. Wiley-Blackwell; 2010.

[45] Kamara J, Anumba C, Carrillo P. A CLEVER approach to selecting a knowledge management strategy. International Journal of Project Management 2002;20 (3):205-11

[46] Fay M, Morrison M. Infrastructure in Latin America and the Caribbean. Recent developments and key challenges. The World Bank; 2007.

[47] Pietrosemoli L, Rodríguez Monroy C. Renewable energy infrastructure. A challenge for Venezuelan industrial construction. In: Tenth Latin American and Caribbean conference (LACCEI; 2012), Panama.

[48] World Economic Forum The Global competitiveness report 2011-2012; 2011

[49] Sequera L. Impacto de las TIC en la aplicación de políticas públicas caso Venezuela. In: XII Congreso de estudiantes y graduados de ciencias políticas UCV. Revista UCV124 2002:409-28.

[50] de la Vega I. Cienciometría y política científica en la periferia: el caso Venezuela. Revista Espacios 2003;24(1)
[51] Corpoelec. 〈http://www.corpoelec.gob.ve〉. Revised; September 2012

[52] Portillo C. Crisis eléctrica en Venezuela. Dónde estamos y hacia dónde vamos, Foro Energía y Petróleo.Venezuela: Universidad del Zulia; 2011.

[53] Batlle C, Barroso L, Pérez-Arriaga l. The changing role of the state in the expansion of electricity supply in Latin America. Energy Policy 2010;38:7152-60.

[54] Anbary F. The Guri dam; 2006. Project Management Institute.

[55] Méndez N. Hitos del proceso histórico-social de la ingeniería venezolana. Universidad Central de Venezuela 2010;25(2):51-66.

[56] Revista de Obras Públicas. Presa y central de Caruachi. Un Emblemático Proyecto Hidroeléctrico en Venezuela. Dic; 2001. N. 3416. p. 39-56.

[57] Moxon S. Roll of honour. International Water Power and Dam Construction 1999;51(7):0306-400X

[58] CEN. Comité Européen de Normalisation, 2004. European guide to good Practice in Knowledge management. Part 1: Knowledge management framework. CWA 14924-1. Brussels. 33.

[59] Egbu C, Hayles C, Quintas, P, Hutchinson V, Chimay A, Ruikar K. 2004 Knowledge management for sustainable construction competitiveness. Final report. BNE report 23/2004.

[60] Nonaka l, Toyama R, Konno. SECl, Ba and Leadership: A unified model of dynamic knowledge creation-long range planning vol. 33, issue 1; Feb 2000. p. 5-34.

[61] del Moral A, Pazos J, Rodríguez E, Rodríguez-Patón A, Suárez S. Gestión del Conocimiento. Thomson; 2007.

[62] Zhiliang M. A new approach to reusing construction firm's legacy management information. CIB W78-W102 2011. In: International conference. Sophia Antipolis, France.

[63] Pietrosemoli L, Rodríguez Monroy C. Construction competitiveness and knowledge management. Basic considerations. CIB W78-W102 2011. In: International conference. Sophia Antipolis, France; 2011.

[64] Khalfan M, Maqsood T, Egbu C, Ali Noor M. Supply chain capital in construction industry: a conceptual model. CIB W78-W102 2011. In: International conference. Sophia Antipolis, France; 2011. 